\title{
SEPTUM AND KICKER PULSERS FOR THE LNLS 500-MEV BOOSTER SYNCHROTRON
}

\author{
A.C. Lira, F.C. Arroyo, E.K.C.S. Hayashi, LNLS, Campinas, Brazil
}

\begin{abstract}
Brazilian National Synchrotron Light Laboratory (LNLS) has commissioned its new $500-\mathrm{MeV}$ booster synchrotron injector. In this paper we present an overview of the septum and kicker pulse circuits now in operation. Half-sine wave septum current pulses range from $6.1 \mathrm{kA}$ to $7.3 \mathrm{kA}$ with widths around $80 \mu \mathrm{s}$. Injection and extraction kicker circuits are capable of delivering currents up to $650 \mathrm{~A}$ and $1.2 \mathrm{kA}$, with fall and rise times consistent with the booster revolution period of $112 \mathrm{~ns}$
\end{abstract}

\section{INTRODUCTION}

Brazilian National Synchrotron Light Laboratory (LNLS) [1] has constructed a $1.37-\mathrm{GeV}$ storage-ring facility for research on UV and X-ray, and has successfully operated it since July 1997. Since then, injection into this storage ring has been made from a 120MeV LINAC.

In 1998 the construction of a booster storage ring was proposed [2] to make injection into the $1.37-\mathrm{GeV}$ synchrotron storage ring at a higher level: $500 \mathrm{MeV}$, and since then the construction of the building blocks for this new accelerator has begun. Commissioning of the 500$\mathrm{MeV}$ booster storage ring started in April 2001 [3] with a $0.17 \mathrm{~Hz}$ repetition rate.

With the insertion of the booster injector, a new set of septum and kicker pulsers had to be constructed for both the new injection and extraction into/from the booster. All pulsers were designed, developed and constructed by the Power Electronics Group at LNLS according to the requirements given by the Accelerator Physics Team.

\section{SEPTUM PULSER TOPOLOGY}

All septum pulse circuits are based on half-sine wave circuits. A capacitor bank is constantly and precisely charged to the specified voltage necessary to obtain the desired peak current. At the time the high-current pulse is to be generated a SCR discharges the capacitors into the septum magnet. Table 1 lists the main characteristics of the septum circuits.

All septum magnets have similar construction: ferrite window frame in vacuum. Ferrites are of type $\mathrm{Mn}-\mathrm{Zn}$ $(\rho=150 \Omega . m)$ MN-67 from Magnet Ceramics.

Table 1: Electric characteristics of the septum pulsers.

\begin{tabular}{|c|c|c|c|c|c|c|}
\hline Septum & Function & $\begin{array}{c}\text { Maximum } \\
\text { Capacitor } \\
\text { Voltage (V) }\end{array}$ & $\begin{array}{c}\text { Peak } \\
\text { Current } \\
(\mathbf{k A})\end{array}$ & $\begin{array}{c}\text { Pulse Width } \\
(\mu \mathbf{s})\end{array}$ & $\begin{array}{c}\text { Pulser } \\
\text { Capacitance } \\
(\mu \mathbf{F})\end{array}$ & $\begin{array}{c}\text { Magnet } \\
\text { Inductance } \\
(\mu \mathbf{H})\end{array}$ \\
\hline YSI03 & thin injection into booster & 430 & 7.5 & 52 & 300 & 0.51 \\
\hline XSI01 & thin extraction from booster & 470 & 6.13 & 64 & 300 & 1.03 \\
\hline XSG02 & thick extraction from booster & 530 & 6.13 & 75.8 & 300 & 1.54 \\
\hline XSG05A & thick injection into ring & 550 & 7.1 & 64 & 300 & 1.03 \\
\hline XSG05B & thick injection into ring & 550 & 7.1 & 64 & 300 & 1.03 \\
\hline XSI06 & thin injection into ring & 450 & 4.77 & 53.1 & 200 & 1.03 \\
\hline
\end{tabular}

\subsection{The Septum Pulse Generators}

All the septum pulse generators have the same basic configuration (see Fig. 1). The number of energy-storage capacitors is changed according to the desired peak of current pulse, and respecting for the maximum peak current of the capacitors (800 A each).

A prototype of the chosen topology was put in operation for over 1 million pulses, without showing any failures, at a repetition rate of $1 \mathrm{~Hz}$, which corresponds to an estimated time of operation of 5 years.

*ira@lnls.br
The type of capacitors used plays an important role in the pulser's expectancy of life. A first attempt to use polyester metallized capacitors failed after some hours of operation when some capacitors were damaged. A second and successful attempt was made using self-healing metallized polypropylene capacitors.

In applications with such a high peak current, distributed gate thyristors must be used. In our case we have exhaustively tested the Westcode's R305CH16$\mathrm{F} 2 \mathrm{H} 0$ thyristor which finally was put into operation in all septum pulsers.

A recovery circuit ( $\mathrm{Dr}$ and $\mathrm{Lr}$ ) was added in order to restore some of the energy present at the capacitor bank, which have an opposite (negative) voltage at the end of the half-sine wave current pulse. This helps reducing the 
total loss and avoids the recovery be done via the septum magnet.

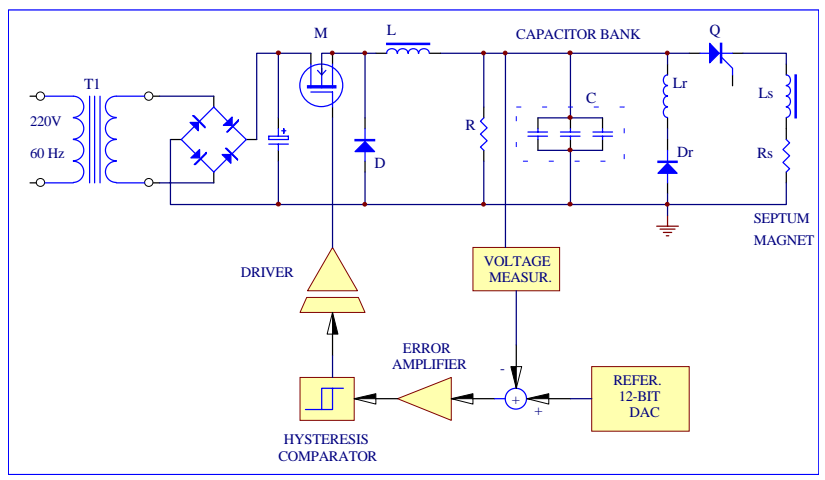

Figure 1: Basic topology of the septum pulser.

Voltage on the capacitor bank is stabilised via a Voltage Limit Control (VLC) that keeps this voltage swinging between two precise and fixed limits (100 $\mathrm{mVpp})$ over the whole range of operation. This makes the capacitor bank voltage insensitive to variations in the mains voltage, since the MOSFET is turned on and off only to keep at a constant value the capacitor-bank mean voltage.

Due to the low repetition rate of the booster, the power dissipated in the septum coil is negligible.

Septum pulsers are placed as close as possible to the septum magnet in order to minimise stray fields and additional inductances. Connection between pulser and septum feed-through is made by a coaxial connection.

Figure 2 shows a typical waveform of a 8-kA peak current pulse.

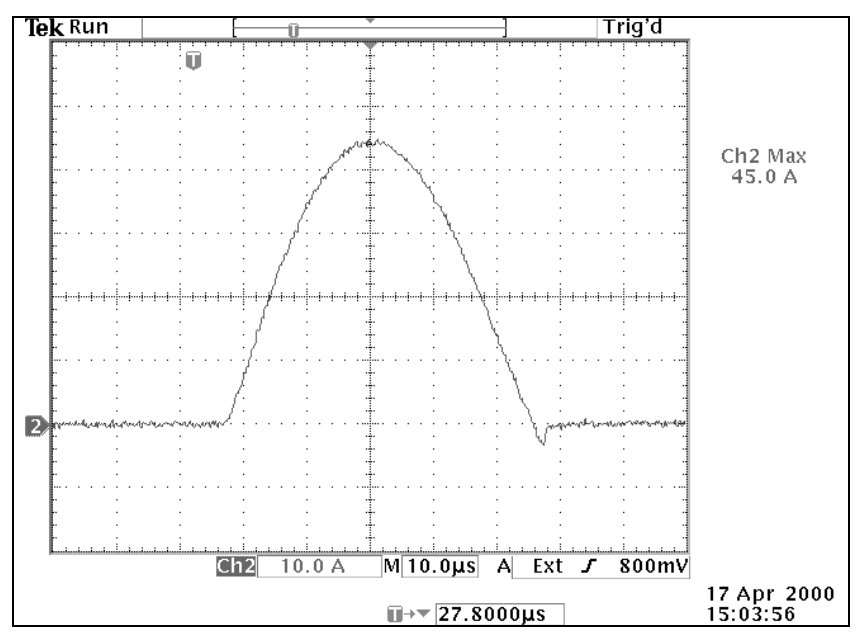

Figure 2: Typical current pulse of the septum circuits (1780 A/div).

\section{KICKER PULSER CIRCUITS}

Booster kicker circuits are based on the design of a Delay Line Pulser where the thyratron is electrically floating from the ground basis [4].

Because of the intrinsic inductances of the kickers we had to split magnet circuits in two halves, each one having its own pulser but the charging high-voltage remains the same for both submodules, which are pulsed at the same time.

Kicker magnets are of the window-frame type inside a vacuum vessel. CMD-5005 high-frequency ferrites from Magnet Ceramics were used. Injection and extraction kicker mechanical design is the same and so are the topologies of the pulser circuits.

Table 2 lists the main parameters of operation for the injection and extraction kickers.

Table 2: Parameters of the kicker pulsers.

\begin{tabular}{|l|c|c|}
\hline \multicolumn{1}{|c|}{ Parameters } & Injection & Extraction \\
\hline Max. PFN voltage & $30 \mathrm{kV}$ & $30 \mathrm{kV}$ \\
\hline PFN impedance & $25 \Omega$ & $12.5 \Omega$ \\
\hline Flat-top current & $0.58 \mathrm{kA}$ & $1.11 \mathrm{kA}$ \\
\hline Rise-time $(10 \%$ to $90 \%)$ & $26.8 \mathrm{~ns}$ & $40.2 \mathrm{~ns}$ \\
\hline Flat-top duration & $220 \mathrm{~ns}$ & $152 \mathrm{~ns}$ \\
\hline Fall-time $(90$ to $10 \%)$ & $46.6 \mathrm{~ns}$ & $85 \mathrm{~ns}$ \\
\hline
\end{tabular}

In order to reduce the rise time for the extraction kicker, a 500-pF peaking capacitor (Cp) was added on the design of this kicker pulser (see fig. 3). An overshoot of $10 \%$ at the rising of the current at the extraction kicker seems to be tolerable and has an acceptable effect on the extracted beam, although a faster rise time would be desirable.

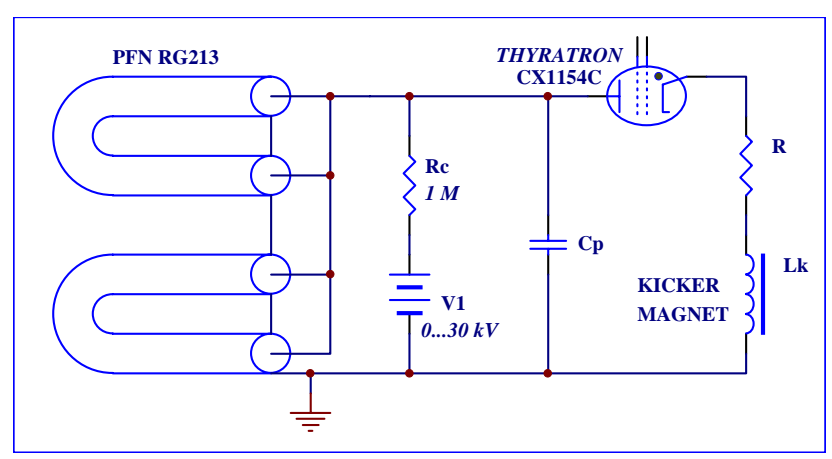

Figure 3: Kicker pulser diagram.

In the diagram, V1 is a high voltage regulated power supply from Glassman. Charging of the pulse-forming network (PFN) is made via a high resistance circuit Rc (1 $\mathrm{M} \Omega$ ) in order to avoid continuos conduction of the thyratron after a pulse has been produced. As the design pulse repetition rate is quite low: $0.2 \mathrm{~Hz}$ maximum, power losses on the resistive charging of the PFN is negligible.

Careful attention was taken during the mechanical design (see fig. 4) of the thyratron housing in order to reduce the EMI and provide for a low inductance circuit since the thyratron itself contributes greatly to the pulser's total stray inductance. A pipe of forced air makes the cooling of the thyratron directly to the cathode flange. Thermostat protection shuts-down auxiliary circuits and the high voltage power supply in case of overheating. 


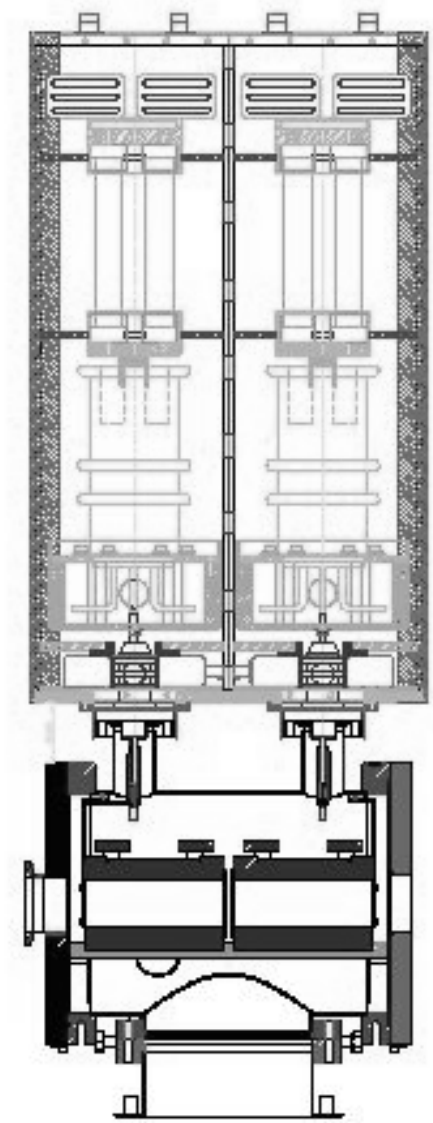

Figure 4: diagram of the thyratron housing and kicker.

During the production of the kicker pulses, the thyratron auxiliary circuits are isolated from the cathode potential by means of CMD-5005 ferrite rings in which five turns of the output auxiliary wires are coiled. This provides for an instantaneous high impedance circuit for the lasting of the pulse.

Auxiliary thyratron circuits for driving the grids, filament and reservoir power supplies were also developed and constructed by the Power Electronics Group at LNLS.

In order to reduce the reflected voltage applied to the thyratron at the end of the pulse duration and to match the PFN impedance $50 \Omega$ non-inductive resistors in parallel are used.

Figures 5 and 6 show the pulse current on the kicker circuits.

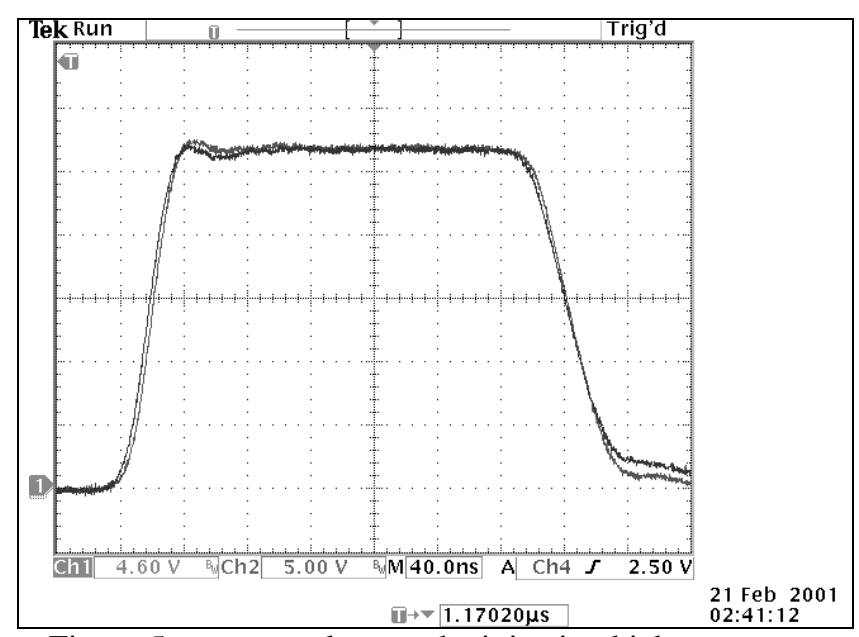

Figure 5: current pulses on the injection kicker magnets $(110 \mathrm{~A} / \mathrm{div})$.

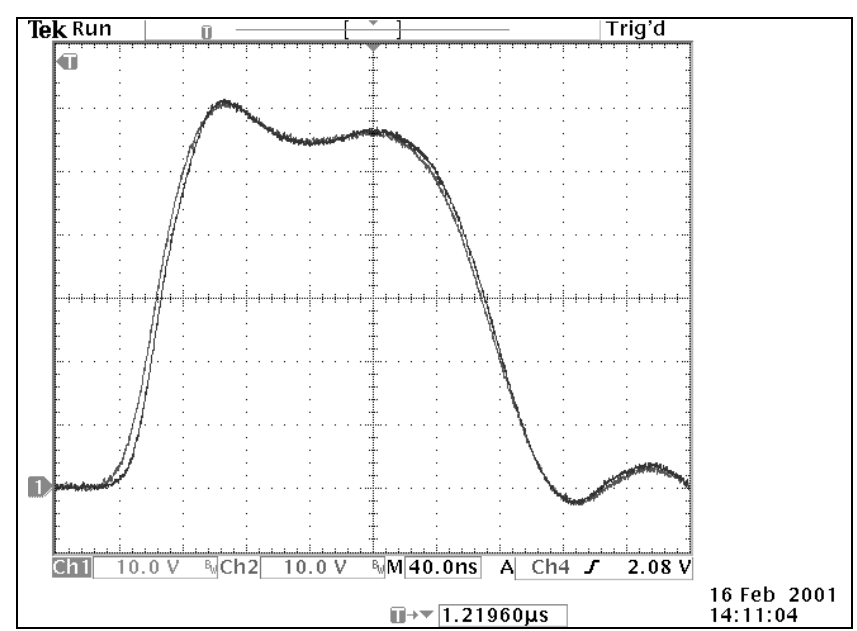

Figure 6: current pulses on the extraction kicker magnets (200 A/div).

\section{REFERENCES}

[1] www.lnls.br

[2] A.R.D. Rodrigues et al, "Design of a Booster for the Brazilian Synchrotron Light Source". EPAC98, Stockholm, Sweden.

[3] P. Tavares et al, "Commissioning of the LNLS 500MeV Booster Synchrotron". These proceedings.

[4] H.-D. Nuhn, R. Boyce, J. Cerino, T. Hosteler, "The SSRL Injector Kickers". SSRL ACD-Note \# 101. June 1991. 